\title{
Integrative Analysis of Surface Runoff and Macropore Flow for Slopes under Rainfall Conditions
}

\author{
Yun Que, ${ }^{1}$ Peiyuan Lin $\mathbb{D}^{2}{ }^{2}$ and Denghui Lin ${ }^{1}$ \\ ${ }^{1}$ College of Civil Engineering, Fuzhou University, Fuzhou, Fujian 350116, China \\ ${ }^{2}$ Department of Civil Engineering, Ryerson University, Toronto, ON, Canada M5B 2K3 \\ Correspondence should be addressed to Peiyuan Lin; peiyuan.lin@ryerson.ca
}

Received 22 June 2017; Revised 22 October 2017; Accepted 13 November 2017; Published 9 January 2018

Academic Editor: Manfred Krafczyk

Copyright (c) 2018 Yun Que et al. This is an open access article distributed under the Creative Commons Attribution License, which permits unrestricted use, distribution, and reproduction in any medium, provided the original work is properly cited.

\begin{abstract}
Estimating runoff and infiltration in slopes is essential to predict flooding and landslide triggering. An approach jointly using a dual-permeability model and a kinematic wave model was proposed for integrative analyses of infiltration and surface runoff of rainwater for slopes with macropores in soils subjected to rainfalls. Laboratory tests were conducted to evaluate the performance of the proposed approach. Analyses showed that the presence of macropores greatly facilitates rainwater movement in the slope and the maximum depth of wetting front could be one order of magnitude larger than in cases without macropores. The influence of rainfall intensity, initial pore water pressure, coefficient of permeability of soil matrix, and slope angle was also examined.
\end{abstract}

\section{Introduction}

Slope stability failures due to short-duration high-intensity rainfalls such as seasonal typhoons and rainstorms are not uncommon in coastal areas of southeastern China. Rainfallinduced slope stability failures (e.g., landslides) are mainly attributed to the infiltration of rainwater which causes changes in pore water pressures and seepage forces [1]. Soil suctions in an unsaturated slope dissipate, totally or partially, with increasing degree of saturation of that slope. The loss of soil suctions results in reduction of shear strength of soils and could eventually lead towards failures of that slope.

Rainwater infiltration and flow within a slope have been extensively studied, for example, Akan and Yen [2], Abbott et al. [3], Garg and Sen [4], Bautista et al. [5], and Banti et al. [6]. When a slope is subjected to a rainfall event, at early stage the rainwater is absorbed by soils at and near the slope surface because of their high infiltration capacity at dry conditions. At this stage, the infiltration rate is equal to the rainfall intensity. As the infiltration continues, the infiltration capacity of the surface soils decreases rapidly and then is exceeded by the rainfall intensity. As such, slope surface runoff takes place and the infiltration rate is now equal to the infiltration capacity of the surface soils under saturated conditions. Models have been developed to describe this rainfall-infiltration-runoff process for slopes where the infiltration capacity of soils across a slope is more or less similar; for example, differences in coefficient of permeability are usually within one order of magnitude [7-10].

However, this type of models was later found inadequate in explaining the occurrence of shallow landslides for a slope subjected to a short-duration high-intensity rainstorm [1]. This is because there are always macropores in a slope commonly due to surface cracking, channels formed by roots of trees, pores caused by animals, and structural cavities in soils due to drying-wetting or freezing-thawing cycles [11]. These macropores form channels where the magnitude of soil permeability is several orders higher than that of the soil matrix (i.e., micropores). The presence of macropores allows rainwater to reach a much greater depth into the slope within a short time. This largely increases the chance for shallow landslides to take place even under short-duration rainfall conditions.

Various models have been developed to simulate rainwater flow in soils with macropores, including dual-porosity model [12], dual-permeability model [13], multidomain model [14], and two-phase model [15]. The dual-permeability model is adopted in this paper. In a dual-permeability model, soils are assumed to consist of a less permeable micropore 
domain (soil matrix) and a highly permeable macropore domain. The flows of rainwater in both domains are governed by two Richards' equations. The two equations are connected through sharing a common term describing the water transfer between the two pore domains. The ability of dual-permeability models in modeling water infiltration and water flow in soils with micro- and macropores has been demonstrated (e.g., [16, 17]).

When a slope is subjected to a short-duration highintensity rainstorm, the rainfall intensity can be reasonably assumed to be much larger than the saturated permeability of the slope surface soils. Under this situation, both flow of rainwater in soils and surface runoff take place simultaneously. The focus of this paper is on integrative analyses of surface runoff and rainwater flow in soil for slopes under rainfall conditions. The surface runoff and the rainwater flow in soil are described using one-dimensional kinematic wave equation [18] and dual-permeability model equation [16] reported in the literature, respectively. The equations are numerically solved using the finite difference method. The ability of the two equations to simulate the rainfall-infiltration-runoff process is demonstrated by the good agreement between the numerical analysis outcomes and the experimental outcomes in laboratory. A parametric study is also carried out to show the influences of rainfall intensity, initial pore water pressure, saturated soil permeability, and slope angle on the rainfallinfiltration-runoff process.

\section{Analytical Models for Slope Surface Runoff and Macropore Flow}

2.1. Kinematic Wave Equation for Slope Surface Runoff. Slope surface runoff takes place when the rainfall intensity exceeds the infiltration capacity of the slope. The surface runoff can be modeled using the one-dimensional kinematic wave equation [18], which is expressed as

$$
\frac{\partial H}{\partial t}+\frac{\partial q}{\partial x}=r \cos \alpha-I,
$$

where $H$ is the surface ponding depth $(\mathrm{m}) ; t$ is time (s); $q$ is the flow rate per unit width $\left(\mathrm{m}^{2} / \mathrm{s}\right)$ computed as $\left(1 / n H^{5 / 3} \sin \alpha^{1 / 2}\right)$ with $n$ being Manning's roughness coefficient of slope surface; $x$ is the distance between a certain point at slope surface and the toe of the slope $(\mathrm{m}) ; r$ is the rainfall intensity $(\mathrm{m} / \mathrm{s}) ; \alpha$ is the angle of the slope from the horizontal; and $I$ is the infiltration rate of slope soil $(\mathrm{m} / \mathrm{s})$. In the brackets are the units for the variables in (1). Readers interested in details of derivations of (1) and its application are directed to, for example, Walker and Skogerboe [19] and Huang and Yeh [20].

\subsection{Dual-Permeability Model for Water Flow in Micropore and} Macropore Domains. Dual-permeability models are widely used to simulate water flow in soils with both micro- and macropores (e.g., [21-23]). There are in general two types of dual-permeability models based on model assumptions: (1) water is mobile in macropores while it is immobile in micropores and (2) water is mobile in both micro- and macropores. In this study, dual-permeability model with the second assumption is adopted, which is expressed as [13]

$$
\begin{aligned}
\frac{\partial \theta_{f}}{\partial t} & =\frac{\partial}{\partial z}\left(K_{f} \frac{\partial h_{f}}{\partial z}+K_{f}\right)-\frac{\Gamma_{w}}{w_{f}} \\
\frac{\partial \theta_{m}}{\partial t} & =\frac{\partial}{\partial z}\left(K_{m} \frac{\partial h_{m}}{\partial z}+K_{m}\right)+\frac{\Gamma_{w}}{1-w_{f}} .
\end{aligned}
$$

Here, $\theta_{f}, K_{f}$, and $h_{f}$ are volumetric water content (dimensionless), unsaturated permeability coefficient $(\mathrm{m} / \mathrm{s})$, and pressure head $(\mathrm{m})$ in macropores, respectively; $\theta_{m}$, $K_{m}$, and $h_{m}$ are volumetric water content (dimensionless), unsaturated permeability coefficient $(\mathrm{m} / \mathrm{s})$, and pressure head $(\mathrm{m})$ in soil matrix (i.e., micropores), respectively; $z$ is depth taken to be positive downward $(\mathrm{m}) ; w_{f}$ is ratio of volume of macropores to volume of the total soil (dimensionless); $\Gamma_{w}$ is water transfer rate between soil matrix and macropores $(1 / \mathrm{s})$.

Gerke and van Genuchten [16] proposed a first-order expression for the water transfer rate $\left(\Gamma_{w}\right)$ assuming $\Gamma_{w}$ is proportional to the difference in pressure head between the macropore and soil matrix domains. The expression of $\Gamma_{w}$ is $[16,17]$

$$
\Gamma_{w}=\frac{\beta}{d^{2}} r_{w} K_{a}\left(h_{f}-h_{m}\right)
$$

where $\beta$ is geometric shape factor of soil aggregates, that is, $\beta=3$ for cubic soil aggregates and $\beta=15$ for spherical soil aggregates; $\beta=3$ is adopted in the analyses that are presented later in this study. The parameter $d$ is half width of the soil matrix or thickness of the matrix mantle in the case of hollow cylindrical geometry $(\mathrm{m}) ; r_{w}$ is a nondimensional scaling factor which can be typically taken as 0.4 [17]; and $K_{a}$ is effective permeability coefficient at the macropore-soil matrix interface, which is commonly defined as an arithmetic average relating to both $h_{m}$ and $h_{f}$ as follows [24, 25]:

$$
K_{a}=0.5\left[K_{a}\left(h_{f}\right)+K_{a}\left(h_{m}\right)\right]
$$

\section{Numerical Method to Solve the Slope Surface Runoff and Macropore Flow Models}

It is generally difficult to derive analytical solutions for (1), (2a), and (2b) even under simple initial and boundary conditions. In this study, the finite difference method was adopted to numerically solve the equations. The following presents the discretization of the equations, the convergence criteria for numerical calculations, and the steps to carry out an integrative analysis. The numerical calculations were performed using Matlab ${ }^{\mathrm{TM}}$.

3.1. Discretization of Equations. The kinematic wave equation of slope surface runoff (1) is discretized based on time and 
space using the Lax-Friedrichs method [26]. The discretized equation can be written as

$$
\begin{aligned}
H_{i}^{t+1}= & \frac{1}{2}\left(H_{i+1}^{t}+H_{i-1}^{t}\right) \\
& -\frac{\Delta t \sin \alpha^{1 / 2}}{2 n \Delta x}\left[\left(H_{i+1}^{t}\right)^{5 / 3}+\left(H_{i-1}^{t}\right)^{5 / 3}\right] \\
& +r \Delta t \cos \alpha-I \Delta t,
\end{aligned}
$$

where $\Delta t$ and $\Delta x$ are computation time and space steps, respectively. Note that in the discretization $q$ is equal to $\left(1 / n H^{5 / 3} \sin \alpha^{1 / 2}\right)$ as noted earlier.

Similarly, the macropore flow equations ((2a) and (2b)) are discretized using the Alternating Direction Implicit Method [27], which is expressed as [28]

$$
\begin{aligned}
& \frac{\theta_{f, i}^{t+1}-\theta_{f, i}^{t}}{\Delta t} \\
& =\frac{K_{f, i+1 / 2}^{t+1}\left(\theta_{f, i+1}^{t+1}-\theta_{f, i}^{t+1}\right)-K_{f, i-1 / 2}^{t+1}\left(\theta_{f, i}^{t+1}-\theta_{f, i-1}^{t+1}\right)}{\Delta z^{2}} \\
& \quad+\frac{K_{f, i+1}^{t}-K_{f, i-1}^{t}}{2 \Delta z}-\frac{\beta K_{a} r_{w}}{w_{f} \alpha^{2}}\left(h_{f, i}^{t}-h_{m, i}^{t}\right), \\
& \frac{\theta_{m, i}^{t+1}-\theta_{m, i}^{t}}{\Delta t} \\
& \quad \frac{K_{m, i+1 / 2}^{t+1}\left(\theta_{m, i+1}^{t+1}-\theta_{m, i}^{t+1}\right)-K_{m, i-1 / 2}^{t+1}\left(\theta_{m, i}^{t+1}-\theta_{m, i-1}^{t+1}\right)}{\Delta z^{2}} \\
& \quad+\frac{K_{m, i+1}^{t}-K_{m, i-1}^{t}}{2 \Delta z}+\frac{\beta K_{a} r_{w}}{\left(1-w_{f}\right) \alpha^{2}}\left(h_{f, i}^{t}-h_{m, i}^{t}\right) .
\end{aligned}
$$

3.2. Convergence Criteria for Numerical Computation. The philosophy of selecting convergence criteria is that the computation outcomes should be sufficiently accurate while the computation should be numerically efficient. Previous studies [7] have shown that a satisfactory convergence criterion can be set as the difference in the computation outcomes of two successive computation steps is no larger than $0.1 \%$. This convergence criterion is adopted here and mathematically, it is expressed as

$$
\begin{aligned}
\left|\frac{H_{i}^{t, k+1}-H_{i}^{t, k}}{H_{i}^{t, k+1}}\right| & \leq 0.1 \%, \\
\left|\frac{\theta_{f, i}^{t, k+1}-\theta_{f, i}^{t, k}}{\theta_{f, i}^{t, k+1}}\right| & \leq 0.1 \%, \\
\left|\frac{\theta_{m, i}^{t, k+1}-\theta_{m, i}^{t, k}}{\theta_{m, i}^{t, k+1}}\right| & \leq 0.1 \%,
\end{aligned}
$$

where $k$ is the $k$ th computation step.
3.3. Steps to Perform Integrative Analysis of Slope Surface Runoff and Macropore Flow. Analyses considering both slope surface runoff and macropore flow are conducted based on infiltration capability and water supply rate on the slope surface. The water supply rate depends on rainfall intensity and existing ponding depth. When the infiltration rate of the slope surface soil is larger than the water supply rate, all the water is absorbed by the soil. In this case water only flows in both macropores and soil matrix (no surface runoff) and (2a) and (2b) are employed for analysis. As the water supply rate exceeds the infiltration rate, slope surface runoff also takes place and (1), (2a), and (2b) are needed for analysis. Steps to perform integrative analyses are outlined as follows.

Step 1 (determine soil infiltration rate, $I$, at slope surface). Since the slope soil consists of both domains of macropore and micropore, the total infiltration rate of the soil is the sum of infiltration rates of both domains. Based on the discretization of the macropore flow equation ((2a) and (2b)), the soil infiltration rate can be determined as [25]

$$
\begin{aligned}
I_{m} & =-\frac{0.5\left(K_{m, 0}+K_{m, 1}\right)\left(h_{m, 1}-Y\right)}{\Delta z}, \\
I_{f} & =-\frac{0.5\left(K_{f, 0}+K_{f, 1}\right)\left(h_{f, 1}-Y\right)}{\Delta z}, \\
I & =I_{m}+I_{f} .
\end{aligned}
$$

Here, $I_{m}, I_{f}$, and $I$ are infiltration rate for soil matrix, macropore, and the total soil at the slope surface, respectively. Parameters $K_{m, 0}$ and $K_{m, 1}$ are permeability coefficients of soil matrix at Node 0 and Node 1 , respectively. Node 0 is on the slope surface and Node 1 is the first node along depth (i.e., $z$ direction) as shown in Figure 1. Parameter $h_{m, 1}$ is pressure head of soil matrix at Node 1 . For the macropore domain, parameters of the same meaning are denoted as $K_{f, 0}, K_{f, 1}$, and $h_{f, 1}$. Parameter $Y$ is available water from rain and existing surface ponding on the slope surface which is calculated as

$$
Y=H+r \Delta t \text {. }
$$

At initial conditions, for example, at the beginning of a rainfall, there is no surface ponding and $H$ is equal to 0 .

Step 2 (calculate water supply rate, $R_{s}$ ). The water supply rate $\left(R_{s}\right)$ is the available water over a small time interval, which is mathematically expressed as

$$
R_{s}=\frac{Y}{\Delta t}=r+\left(\frac{H}{\Delta t}\right)
$$

Step 3 (set boundary conditions). The boundary conditions are set by comparing the soil infiltration rate, $I$, to the water supply rate, $R_{s}$. If $I>R_{s}$, then the actual infiltration is controlled by $R_{s}$. In this case, water only flows in macropores and soil matrix and the boundary condition for analysis using (2a) and (2b) is

$$
h_{0}=h_{1}+2\left[\frac{R_{s} \Delta z}{\left(K_{m, s}+K_{m, 1}\right)}\right],
$$




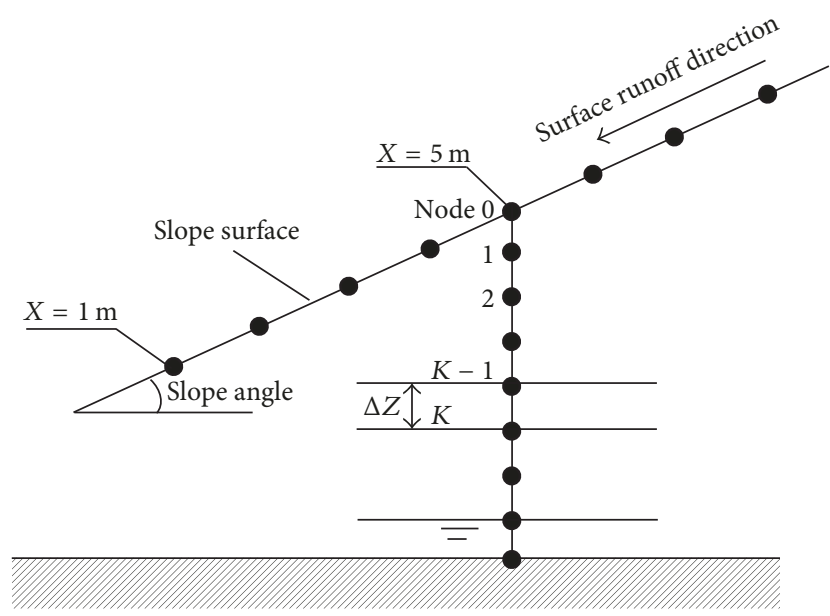

FIGURE 1: Discretization of slope geometry for numerical analysis using finite difference method.

where $h_{0}$ is the pressure head at the boundary node, that is, Node $0 ; h_{1}$ is the pressure head at Node $1 ; K_{m, s}$ is the permeability coefficient of soil matrix under saturated conditions; $K_{m, 1}$ is the permeability coefficient of soil matrix at Node 1.

If $I<R_{s}$, then the infiltration is $I$. The boundary condition for (2a) and (2b) can be defined as

$$
h_{0}=Y \text {. }
$$

Step 4 (compute the volumetric water contents, $\theta_{m, i}$ and $\theta_{f, i}$, given initial values of $K\left(\theta_{m}\right)$ and $\left.K\left(\theta_{f}\right)\right) . K\left(\theta_{m}\right)$ and $K\left(\theta_{f}\right)$ are soil water characteristic curves relating $K_{m}$ and $K_{f}$ to $\theta_{m}$ and $\theta_{f}$, respectively.

If $I>R_{s}$, compute $\theta_{m, i}$ at each node using the boundary condition of (11) and (2b) (discretized form (6b)).

If $I<R_{s}$, then (1) is used to determine the ponding depth $H$ with boundary conditions described as (12). Equations (2a) and (2b) or equivalently the discretized forms (6a) and (6b) are adopted to calculate $\theta_{m, i}$ and $\theta_{f, i}$.

Step 5 (check the satisfaction of convergence criteria of (7a) and (7b)). If both (7a) and (7b) are satisfied simultaneously, the analysis continues to next time step until the end of rainfall; otherwise, rerun the analysis from Step 4 by assuming different initial values of $K\left(\theta_{m}\right)$ and $K\left(\theta_{f}\right)$.

The steps to carry out integrative analyses of slope surface runoff and macropore flow are summarized in the flow chart shown in Figure 2.

\section{Evaluation of Performance of the Surface Runoff and Macropore Flow Model}

4.1. Laboratory Tests. Laboratory tests were conducted to simulate the slope surface runoff and macropore flow process. Monitoring data from laboratory tests were then used to verify the proposed method of jointly using (1), (2a), and (2b) for analysis. Figure 3 shows the setting of laboratory tests. A typical silty clay sampled from a slope site in Wuyishan,
China, was used as the soil matrix. A coarse sand was used to simulate the macropore domain. Both soils were placed in a plexiglass box which was $100 \mathrm{~cm}$ (length) $\times 50 \mathrm{~cm}$ (width) $\times$ $70 \mathrm{~cm}$ (depth) (Figure 3(a)). The slope angle was set as $15^{\circ}$. The variation of soil water contents was monitored and recorded using TDR (time-domain reflectometer) probes.

A rainfall simulator system similar to that used by $\mathrm{Wu}$ et al. [29] was built. The rainfall simulator system consisted of a pump, valves, PVC (Polyvinyl Chloride) pipes, pressure gauges, and raindrop generator as shown in Figure 3(b). To assess the sprinkling homogeneity of the rainfall simulator system, three graduated cylinders were placed at points A, $\mathrm{B}$, and $\mathrm{C}$ at the bottom of the plexiglass box, as shown in Figure 3(c). The system was then initiated to simulate a rainfall with "nominal" intensity of $6.25 \mathrm{~mm} / \mathrm{h}$ for one hour. The water amounts collected by the three graduated cylinders were recorded. This test was repeated for five times and the average values for the cylinders at points $\mathrm{A}, \mathrm{B}$, and $\mathrm{C}$ were 6.4 , 6.7 , and $6.0 \mathrm{~mm} / \mathrm{h}$, respectively, which were basically close to the nominal value of $6.25 \mathrm{~mm} / \mathrm{h}$. Hence, the performance of the rainfall simulator system was considered satisfactory from the perspective of sprinkling homogeneity. Test procedures to simulate the slope surface runoff and macropore flow process are described in detail in the following.

Step 1. The plexiglass box was sealed to be impervious for all sides. While at the bottom of the box, small holes with a diameter of $5 \mathrm{~mm}$ were drilled at a spacing of $10 \mathrm{~cm}$ in both horizontal directions. A layer of geotextile was then placed at the bottom. This was done to simulate a free-drainage boundary condition.

Step 2. The box was filled with silty clay layer by layer with each of $5 \mathrm{~cm}$ thick. The initial volumetric water content was about $15 \%$. Each clay layer was compacted to about $85 \%$ degree of compaction. Here, the degree of compaction is the ratio of dry soil unit weight to the maximum dry soil unit weight. The maximum dry soil unit weight is typically determined through the standard proctor test [30]. A PVC pipe with a diameter of $2 \mathrm{~cm}$ was placed at the middle of the box (Figure 3(a)) when the filling height reached half of the box height. After the placement of the pipe, filling and compaction of the silty clay were continued. A total of six TDR probes were embedded in the silty clay to measure the water content.

Step 3. The PVC pipe was carefully pulled out after completion of the silty clay filling and compaction. Then, the hole was filled with coarse sand which was used to simulate the macropore domain.

Step 4. A rainfall intensity of $6.25 \mathrm{~mm} / \mathrm{h}$ (equivalently $150 \mathrm{~mm} / \mathrm{d}$ ) was chosen since this is a typical rainfall intensity in typhoon-rainstorm prone area. The rainfall duration was taken as one hour (60 minutes) in the experiment.

4.2. Determination of Input Parameters. The saturated and unsaturated coefficients of permeability must be known before integrative analyses of surface runoff and macropore 


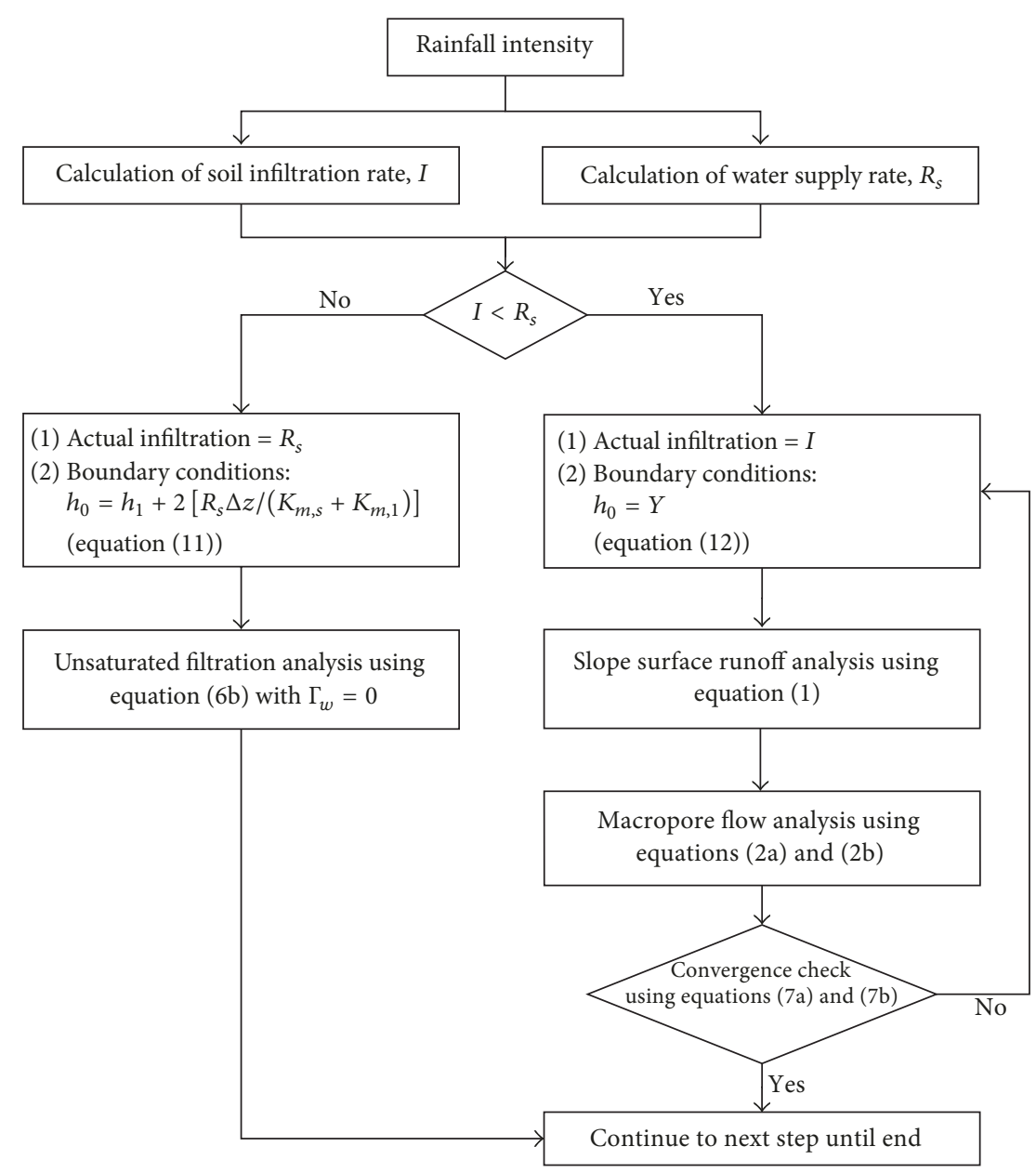

FIGURE 2: Flow chart of integrative analysis of surface runoff and macropore flow under rainfall conditions.

flow can be conducted. These parameters in this study were determined based on the soil water characteristic curve (SWCC) obtained through laboratory experiments.

The van Genuchten model [31] for description of SWCC curves (i.e., water content versus pressure head) was adopted in this paper, which is expressed as

$$
\theta(h)= \begin{cases}\theta_{r}+\frac{\theta_{s}-\theta_{r}}{\left[1+|\eta h|^{\omega}\right]^{(1-1 / \omega)},} & h<0, \\ \theta_{s}, & h \geq 0,\end{cases}
$$

where $\theta_{r}$ and $\theta_{s}$ are residual and saturated volumetric water contents, respectively. Parameters $\eta$ and $\omega$ are empirical constants dependent on soil types. Parameter $h$ is pressure head as defined earlier in this paper. The filter paper method [31] was used to determine the $\theta_{r}$ and $\theta_{s}$ values and (13) was fitted to experiment results to determine the values for $\eta$ and $\omega$. The outcomes are summarized in Table 1.

The saturated coefficients of permeability for the silty clay $\left(K_{m, s}\right)$ and coarse sand $\left(K_{f, s}\right)$ were measured using falling head and constant head permeability tests, respectively. The results are also shown in Table 1 . Unsaturated coefficients of permeability for both soils can be described using the van Genuchten and Mualem model as $[32,33]$

$$
K(\theta)=K_{s} S_{e}^{1 / 2}\left[1-\left(1-S_{e}^{\omega /(\omega-1)}\right)^{1-1 / \omega}\right]^{2},
$$

where $K_{s}=K_{m, s}$ for soil matrix and $K_{s}=K_{f, s}$ for macropore; $S_{e}$ is the effective degree of saturation defined as

$$
S_{e}=\frac{\theta(h)-\theta_{r}}{\theta_{s}-\theta_{r}}
$$

4.3. Comparisons between Experimental Results and Model Solutions. The water content variation with time (rainfall duration) was recorded by the six TDR probes (i.e., A1, A2, $\mathrm{A} 3, \mathrm{~B} 1, \mathrm{~B} 2$, and B3) at depths of 5,15 , and $25 \mathrm{~cm}$ from the slope surface. The data were collected at a sampling rate of one data point per minute. Figure 4 shows the measured water contents with time. The volumetric water contents $\left(\theta_{m}\right)$ at all depths increase with increasing rainfall duration. The initial $\theta_{m}$ in the micropore domain were about $15 \%$ at all depths (time $=0$ minutes) but increased to about $40 \%, 35 \%, 30 \%$, $28 \%, 27 \%$, and $24 \%$ at points A1, A2, A3, B1, B2, and B3 at time of 60 minutes, respectively. The water content was higher at shallower depth than at greater depth. 


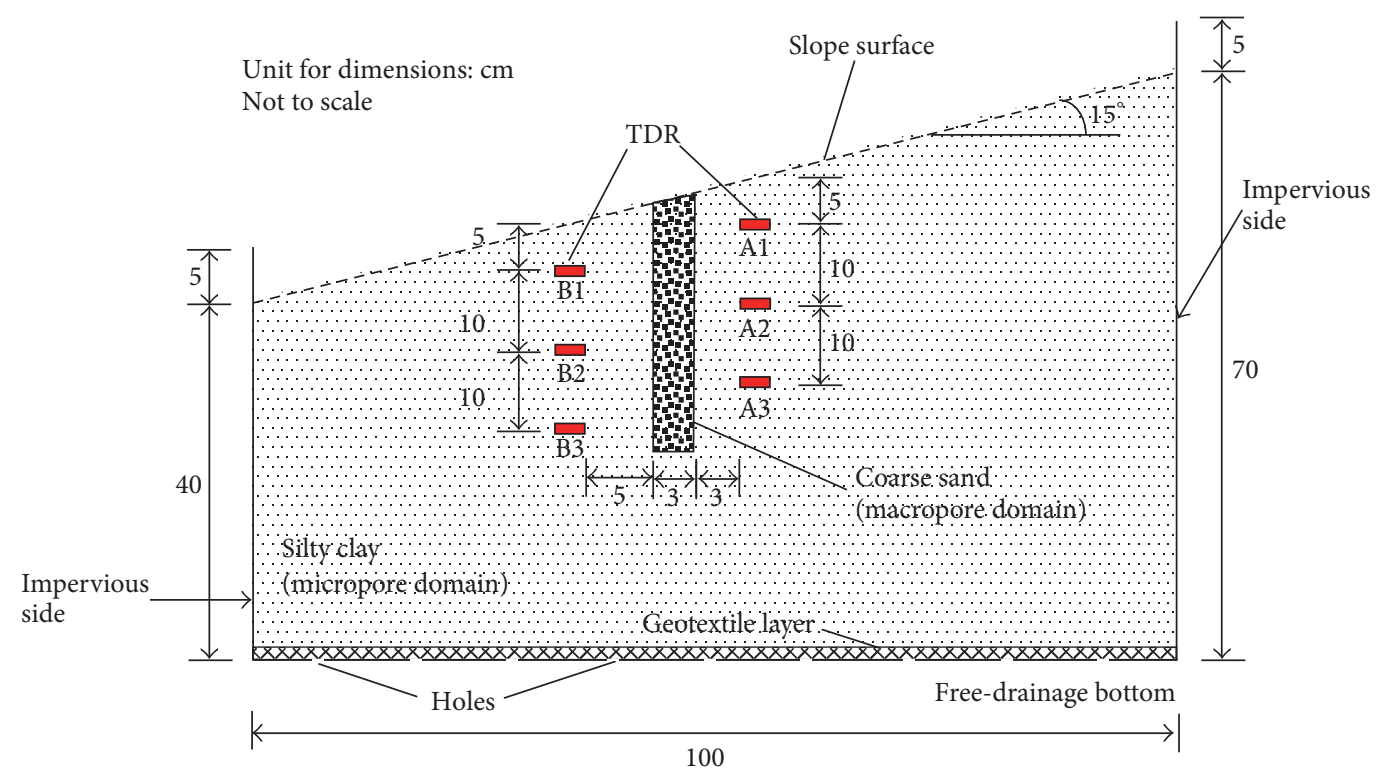

(a)

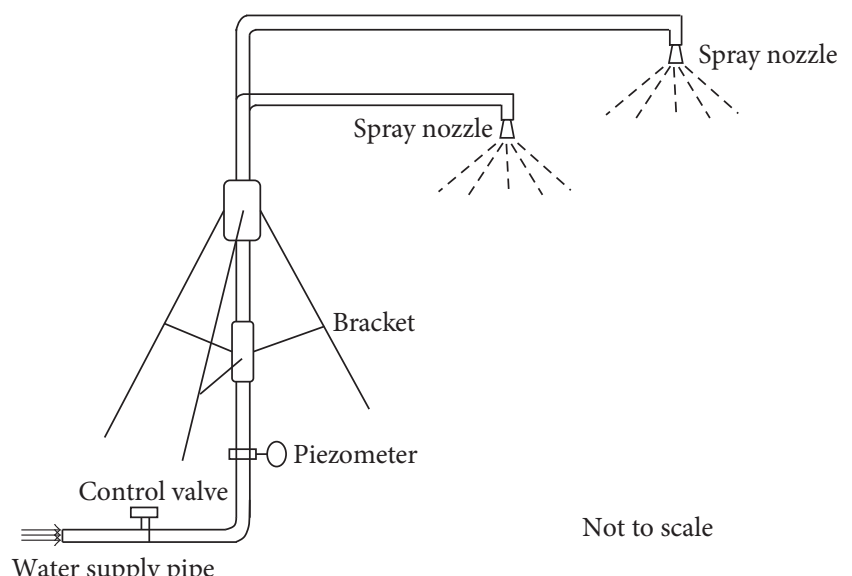

(b)

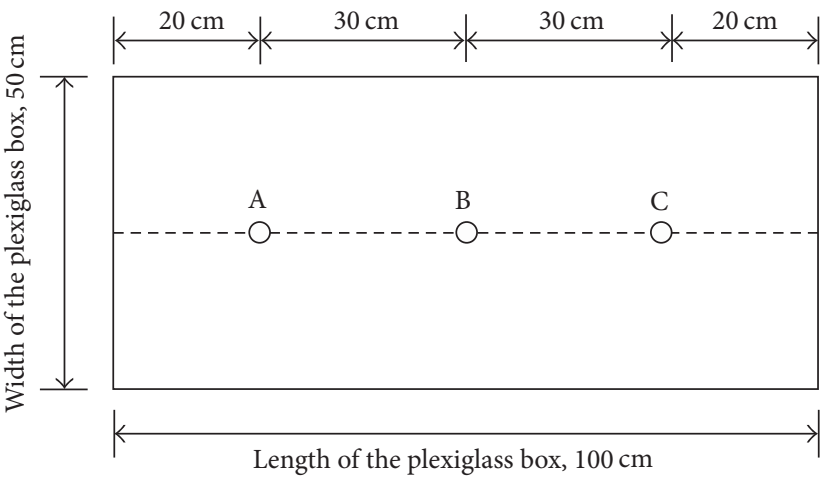

(c)

FIGURE 3: Setting for laboratory tests: (a) physical slope model; (b) rainfall simulator system; and (c) sprinkling homogeneity test.

TABLE 1: Summary of parameters for integrative analysis using the proposed model ((1), (2a), and (2b)).

\begin{tabular}{lcc}
\hline Parameter & Silty clay (soil matrix) & Coarse sand (macropore domain) \\
\hline Residual water content, $\theta_{r}{ }^{*}$ & 0.029 & 0 \\
Saturated water content, $\theta_{s}{ }^{*}$ & 0.37 & 0.50 \\
Shape parameter, $\omega\left(\mathrm{cm}^{-1}\right)$ & 0.058 & 0.098 \\
Shape parameter, $\eta$ & 1.21 & 2.01 \\
Saturated coefficient of permeability $(\mathrm{cm} / \mathrm{s})$ & $5.70 \times 10^{-5}$ & $2.40 \times 10^{-2}$ \\
\hline
\end{tabular}

Note. ${ }^{*}$ These values are volumetric water contents.

For validation purpose, the established model ((1), (2a), and (2b)) was used to numerically compute the water contents at the same points and same depths with time using the input parameters given in Table 1 . The steps to solve the model have been summarized in Figure 2. The predicted water contents using the established model were also plotted in Figure 4 for comparison. The trend in measured $\theta_{m}$ values is well captured (at least visually) by the predicted $\theta_{m}$ values at all depths. The good agreements were confirmed quantitatively using a statistical approach as shown in Figures 5 and 6.

Figure 5(a) shows the plots of measured $\theta_{m}$ values from laboratory tests versus paired predicted $\theta_{m}$ values at points A1, A2, and A3 using the analytical model established in the present paper. Similar plots are shown in Figure 5(b) for points B1, B2, and B3. All datasets in the figures follow closely the $1: 1$ correspondence line. The mean values of bias were 


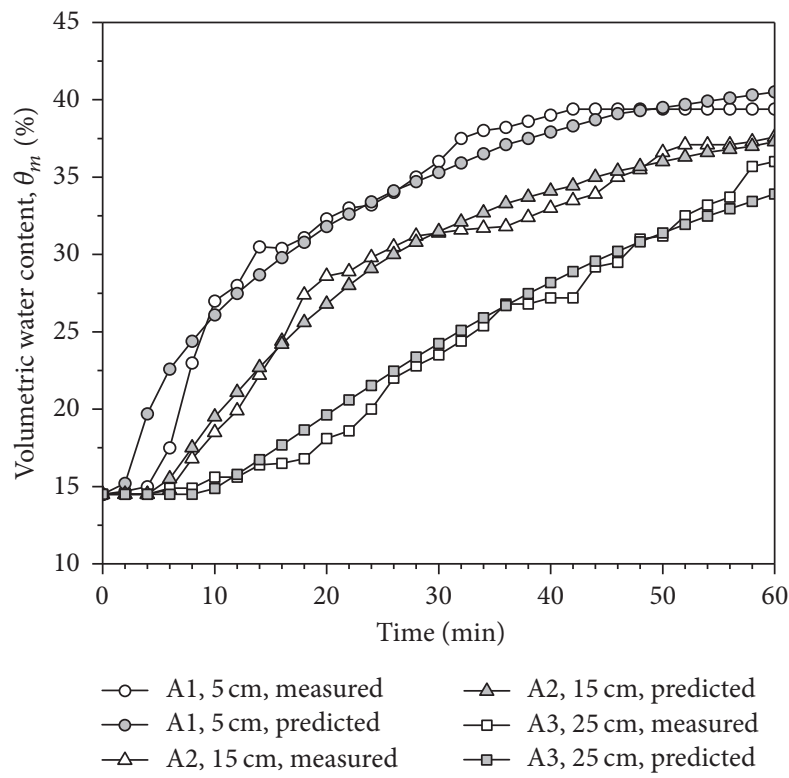

(a)

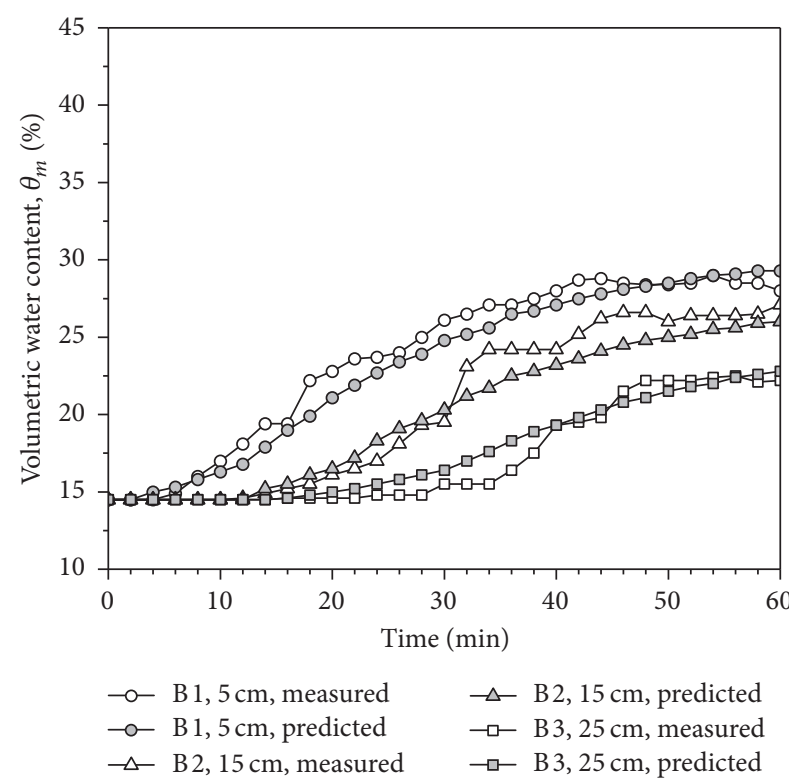

(b)

Figure 4: Plots of measured and predicted volumetric water contents versus time at depths of $5 \mathrm{~cm}, 15 \mathrm{~cm}$, and 25 cm: (a) A1, A2, and A3; (b) $\mathrm{B} 1, \mathrm{~B} 2$, and $\mathrm{B} 3$.

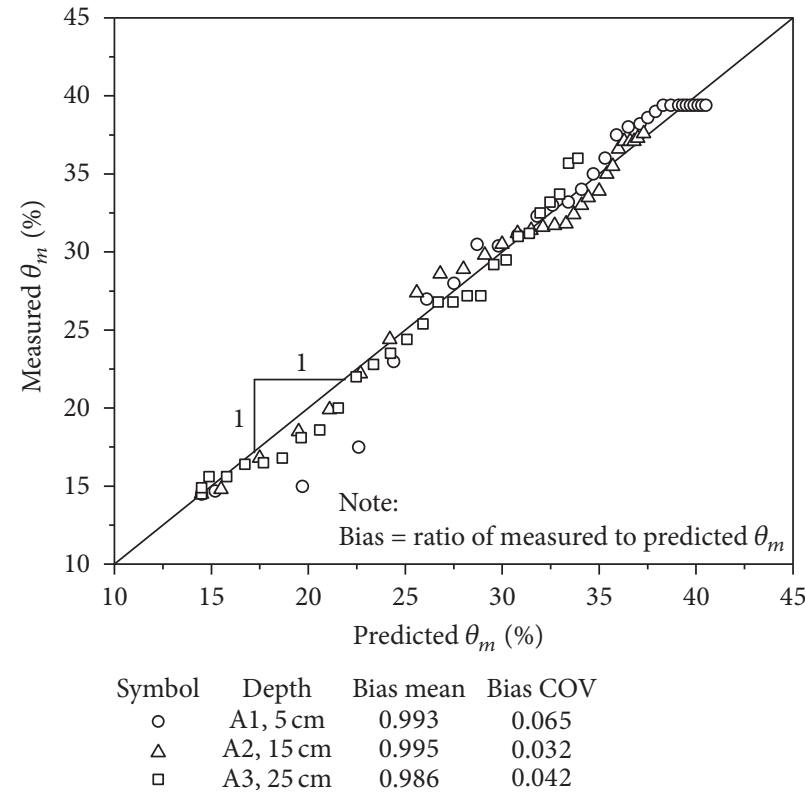

(a)



(b)

FigURE 5: Measured versus predicted volumetric water contents in micropore domain at depths of $5 \mathrm{~cm}, 15 \mathrm{~cm}$, and $25 \mathrm{~cm}$ : (a) A1, A2, and A3; (b) B1, B2, and B3.

close to 1.0 at all points and depths. Here, bias is defined as the ratio of measured to predicted $\theta_{m}$ value. The closeto-one mean values for the three bias datasets indicate that the predictions using the proposed model are satisfactorily accurate on average, regardless of depths. The respective coefficients of variation (COV) of bias values were basically between $3 \%$ and $7 \%$. The COV of bias values were all small, implying small spreads in prediction accuracy.
The bias values were then plotted against the predicted $\theta_{m}$ values as shown in Figures 6(a) and 6(b). Visual inspections suggest that there are no statistical correlations between bias and predicted $\theta_{m}$ values. The observations were confirmed quantitatively using Spearman's rank correlation test. Spearman's rank correlation test is widely used to measure the monotonic relationship (both linear and nonlinear) between two datasets. The $p$ values of Spearman's rank correlation tests 


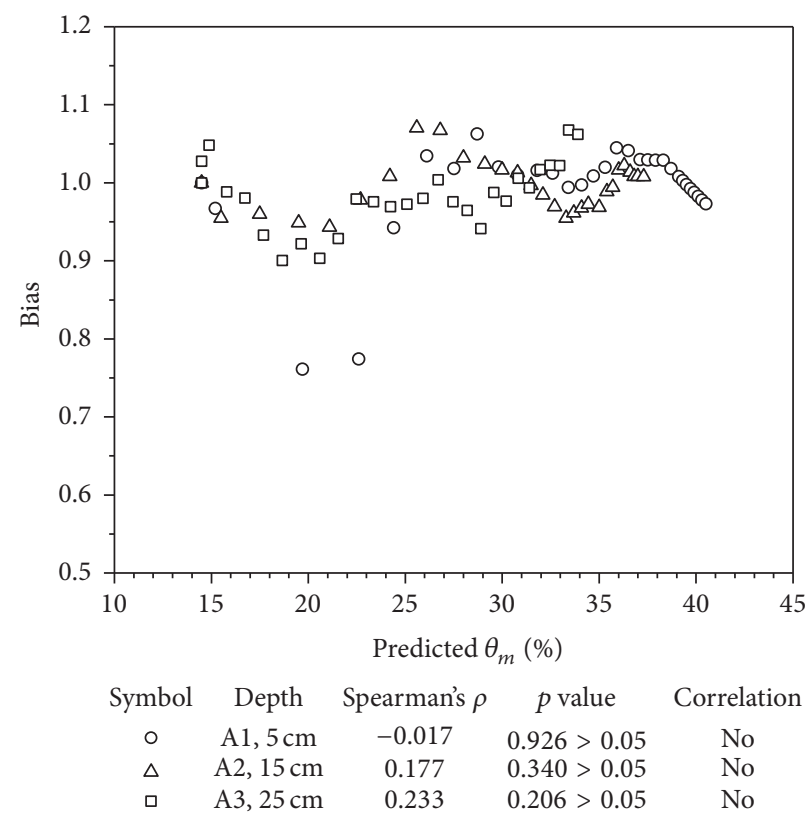

(a)

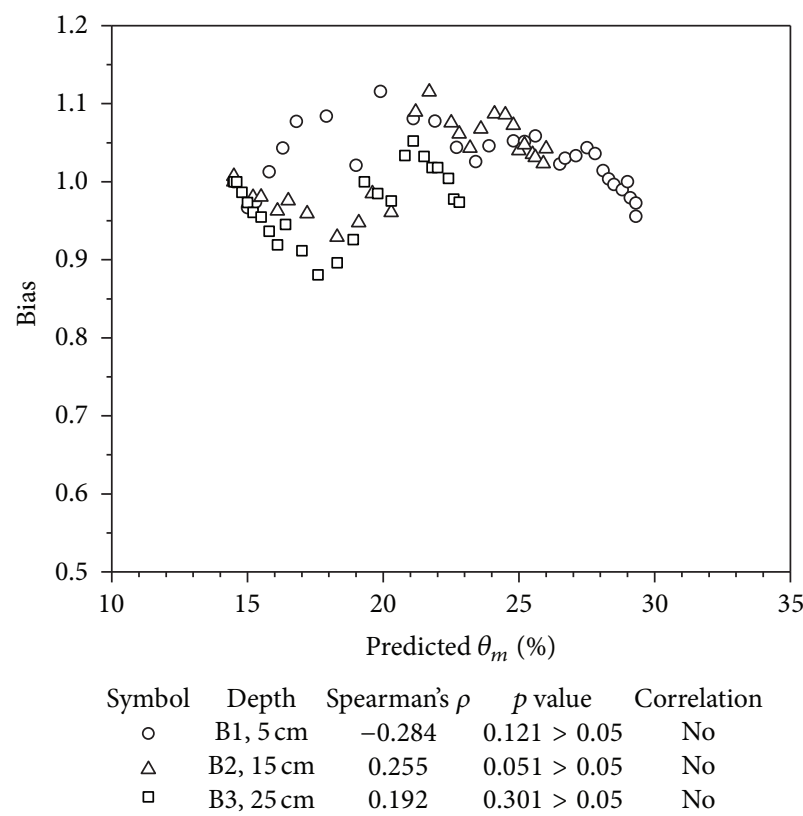

(b)

Figure 6: Bias values against predicted volumetric water contents in micropore domain at depths of $5 \mathrm{~cm}, 15 \mathrm{~cm}$, and $25 \mathrm{~cm}$ : (a) A1, A2, and A3; (b) B1, B2, and B3.



FIGURE 7: Profiles of pressure head with depth at $x=5 \mathrm{~m}$ for $t=1.2 \mathrm{~h}$ and $t=2.4 \mathrm{~h}$.

were larger than 0.05 . This means the rejection of the null hypotheses that the bias values and the predicted $\theta_{m}$ values are correlated at a level of significance of $5 \%$. Hence, based on the mean of bias, COV of bias, and Spearman's rank correlation test outcomes, the performance of the proposed model is judged to be satisfactory. However, it is also important to note that the high accuracy of the analytical model in this study is largely attributed to the fact that the measured $\theta_{m}$ values are obtained under well-controlled laboratory conditions. The accuracy of the model can be expected to be less when applied to simulate in situ slope surface runoff and macropore flow.

\section{Parametric Study}

The parametric study presented in this section was based on a slope with geometry shown in Figure 1. Input parameters and boundary conditions are the same as given in Table 1. Influences of presence of macropores, rainfall intensity, initial pore water pressure, and coefficient of permeability of soil matrix on the maximum depth of wetting front in soil and ponding depth on slope surface are examined. The baseline case is set as rainfall intensity $r=12.5 \mathrm{~mm} / \mathrm{h}$ (equivalently $300 \mathrm{~mm} / \mathrm{d}$ ), initial pore water pressure of $-10 \mathrm{~m}$ (initial pressure head), and permeability coefficient of $K_{m, s}=5.70 \times$ $10^{-5} \mathrm{~cm} / \mathrm{s}$ for soil matrix. In the following analyses, the water content is always for the soil matrix.

5.1. Effect of Presence of Macropores. The presence of macropores in soils greatly increases the infiltration depth of wetting front within the same time period compared to the case with soil matrix only, as shown in Figure 7. For example, the wetting front reaches a maximum depth of about $6 \mathrm{~cm}$ and $8 \mathrm{~cm}$ after 1.2 hours and 2.4 hours of rainwater infiltration, respectively, if there are no macropores in the soils. However, with the existence of macropores the maximum depth of wetting front would reach about $58 \mathrm{~cm}$ for 1.2 hours and $76 \mathrm{~cm}$ for 2.4 hours. The difference between these two cases is about one order of magnitude based on maximum depth of wetting front. This can be expected since the coefficient of 


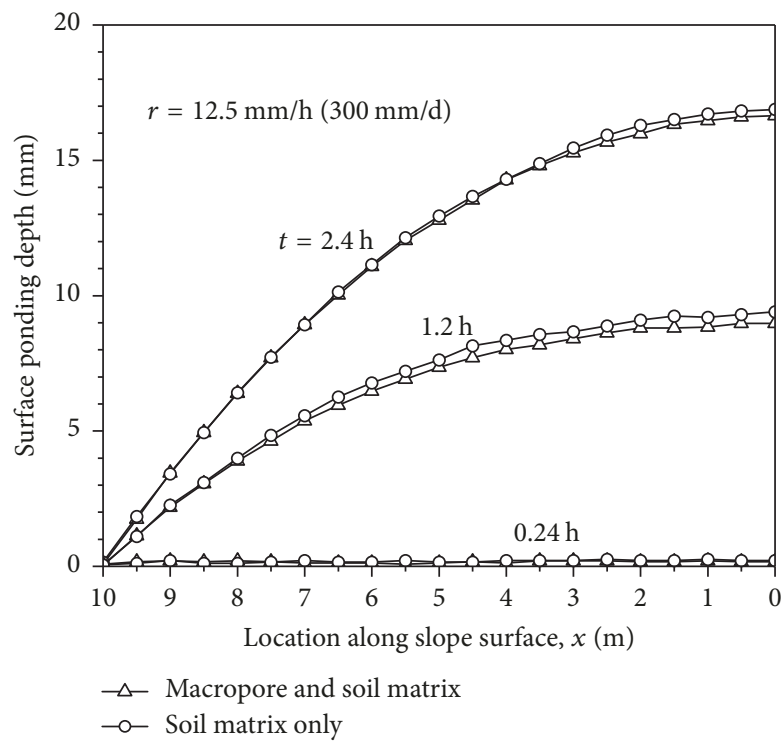

(a)

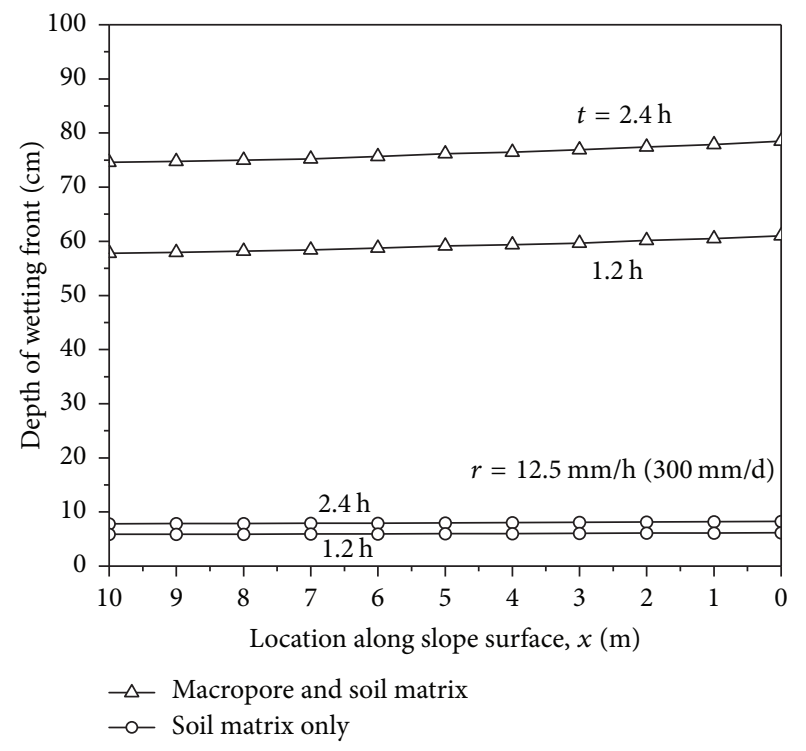

(b)

FIGURE 8: Analyses along slope surface at different rainfall durations: (a) depth of surface ponding; (b) depth of wetting front.

permeability for macropores is three orders larger than that of the soil matrix (Table 1).

The ponding depth on slope surface is smaller if macropores are present in soil, as shown in Figure 8(a). However, the difference is not significant. This can be attributed to the occurrence of surface runoff on an inclined slope, which also explains the observation of larger ponding depth at lower part of the slope. The effect of presence of macropores can be expected to be larger on smoother slopes, that is, smaller slope angle.

Since the ponding depth varies along the slope surface, the boundary pressure in (11) also varies at each point " $x$ ". This results in different infiltration rates and thus depths of wetting front corresponding to different $x$ locations, as shown in Figure 8(b). Within the same time period, the closer to the toe of the slope (i.e., smaller $x$ ), the higher the ponding depth, and hence the deeper the wetting front. However, the difference in depths of wetting front is small due to the fact that the difference in boundary pressures caused by different ponding depths is small.

Figure 9 shows the accumulation of slope surface ponding at $x=1 \mathrm{~m}$ and $x=5 \mathrm{~m}$ with increasing duration of rainfall. At the early stage of the rainfall event, there is basically no surface ponding since all rainwater is absorbed into the soil. As the rainfall lasts, the soil near the slope surface becomes saturated and surface runoff takes place. It takes longer time for surface runoff to take place on a slope with macropores; however, the difference of time for initiation of surface runoff on slopes with and without macropores is not significant in the example used for parametric analyses in this study.

\subsection{Sensitivity Analysis for Pressure Head (Depth of Wetting} Front) in the Slope. The influences of rainfall intensity, initial pressure head, saturated permeability coefficient of soil matrix, and slope angle on the pressure head profile in the

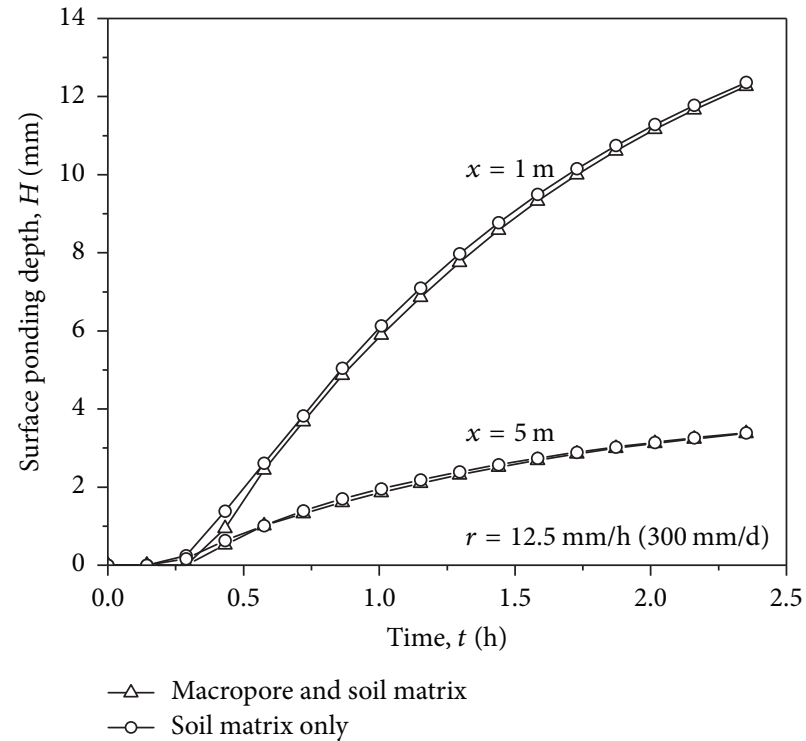

FIGURE 9: Accumulation of surface ponding at $x=1 \mathrm{~m}$ and $x=5 \mathrm{~m}$ with increasing time of rainfall duration.

slope are examined in this section. Their influences on the surface ponding depth are presented in the next section.

Keeping other input parameters constant, the rainfall intensity was varied from $3.33 \mathrm{~mm} / \mathrm{h}(80 \mathrm{~mm} / \mathrm{d})$ to $12.5 \mathrm{~mm} / \mathrm{h}$ $(300 \mathrm{~mm} / \mathrm{d})$ to examine its effect on computed maximum depth of wetting front and surface ponding. Figure 10(a) shows the maximum depths of wetting front corresponding to different rainfall intensities for slopes with soil matrix only and with both soil matrix and macropores. The effect of rainfall intensity on wetting front depth is practically negligible for slopes without macropores, that is, with soil 


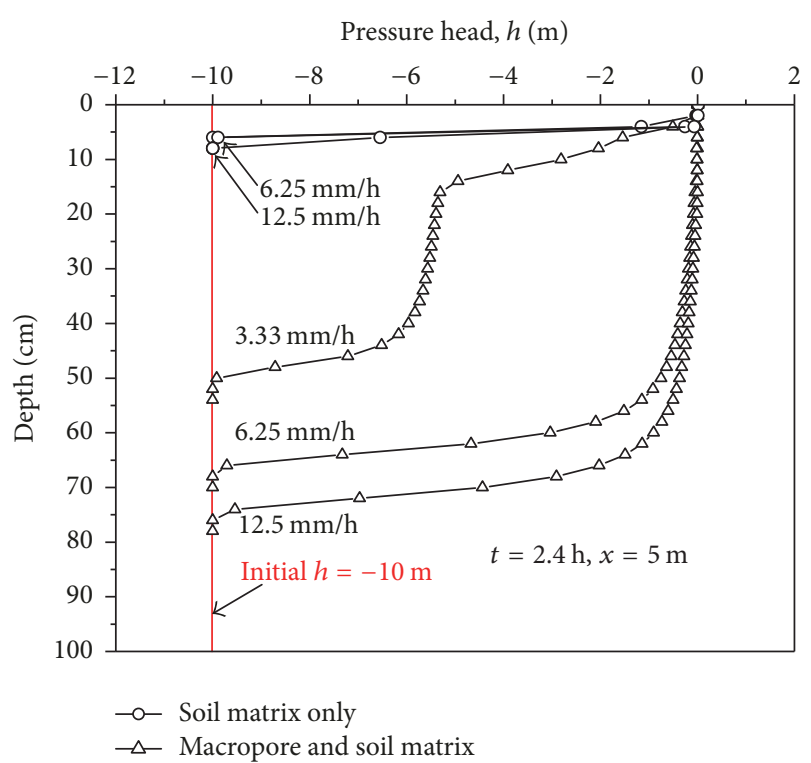

(a)

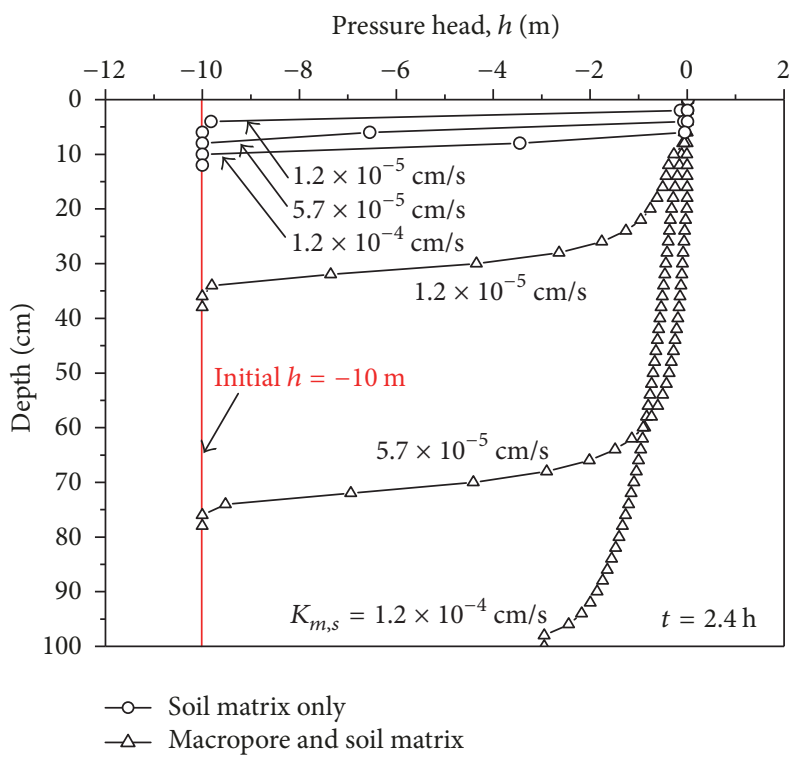

(c)



(b)



(d)

FIGURE 10: Analysis of influential factors on pressure head in the slope ( $x=5 \mathrm{~m}, t=2.4 \mathrm{~h}$ ): (a) rainfall intensity; (b) initial pressure head; (c) saturated permeability coefficient of soil matrix; (d) slope angle.

matrix only. This is due to the fact that the three rainfall intensities used for analyses were all much higher than the coefficient of permeability of the soil matrix under saturated conditions. For slopes with macropores, larger maximum depth of wetting front was found for higher intensity of rainfall, for instance, about $50 \mathrm{~cm}$ for rainfall intensity of $3.33 \mathrm{~mm} / \mathrm{h}$ but about $76 \mathrm{~cm}$ for rainfall intensity of $12.5 \mathrm{~mm} / \mathrm{h}$.

The initial conditions of pore water pressure expressed as pressure head was set at $-0.5 \mathrm{~m},-5 \mathrm{~m}$, and $-10 \mathrm{~m}$. The initial pore water pressure of $-0.5 \mathrm{~m}$ was intended to simulate slopes at a state close to fully saturated conditions, while the value of $-10 \mathrm{~m}$ was used for slopes under dry conditions. The plots of pressure head in the depth direction are shown in Figure 10(b) for analyses using different initial pore water pressures. For slopes with macropores, soils within a depth of about $60 \mathrm{~cm}$ become saturated after 2.4 hours of rainfall, regardless of the initial pore water pressures.

Figure 10(c) shows the depths of wetting front with respect to three different coefficients of permeability assumed for the soil matrix, that is, $K_{m, s}=1.2 \times 10^{-5} \mathrm{~cm} / \mathrm{s}, 5.7 \times$ $10^{-5} \mathrm{~cm} / \mathrm{s}$, and $1.2 \times 10^{-4} \mathrm{~cm} / \mathrm{s}$. The wetting front depth was greatly influenced by $K_{m, s}$. As $K_{m, s}$ increases, the soil matrix is more permeable and the rainwater infiltrates into the soils more rapidly. The effect of $K_{m, s}$ is insignificant within the range under consideration for the case of slopes with soil matrix only. 


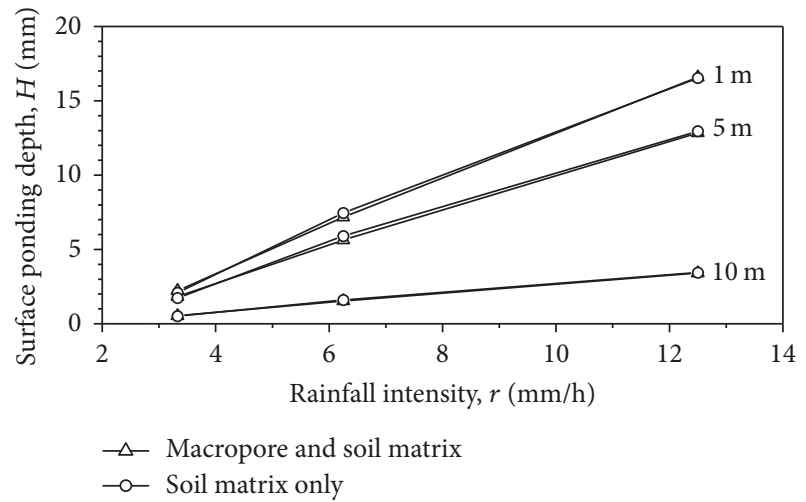

(a)

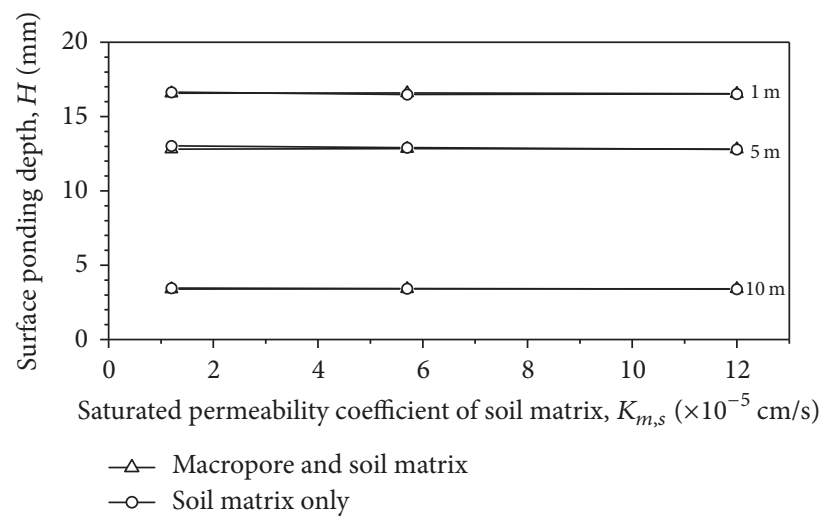

(c)



(b)



(d)

Figure 11: Analysis of influential factors on surface ponding depths of three different $x$ locations $(t=2.4 \mathrm{~h}$ ): (a) rainfall intensity; (b) initial pressure head; (c) saturated permeability coefficient of soil matrix; (d) slope angle.

Figure 10(d) shows the effects of slope angle on the infiltration of rainwater. The depth of wetting front decreases from about $80 \mathrm{~cm}$ to about $60 \mathrm{~cm}$ as the slope angle correspondingly increases from $5^{\circ}$ to $25^{\circ}$ based on a $t=2.4 \mathrm{~h}$ rainfall period. This is because the surface runoff flows at higher speeds on steeper slopes, which results in less surface ponding depths and thus shallower depths of the wetting front.

5.3. Sensitivity Analysis for Surface Ponding Depth along the Slope. The surface ponding depth increases with increasing rainfall intensity as shown in Figure 11(a). The surface ponding depths appear to be roughly the same for slopes with and without macropores, although larger ponding depth is obtained for the latter case.

Figure 11(b) showed that smaller initial pore water pressures lead to larger surface ponding depths. At $x=10 \mathrm{~m}$, the difference in surface ponding depths is negligible, while at $x=1 \mathrm{~m}$, the difference reaches about $3 \mathrm{~mm}$. In general, the surface ponding depths are similar regardless whether there are macropores in slopes or not.

The surface ponding depth was much less influenced by $K_{m, s}$ in this analysis, although smaller $K_{m, s}$ value resulted in larger ponding depth. No noticeable difference was found between slopes with and without macropores in this case, as shown in Figure 11(c).
Figure 11(d) shows the effects of slope angle on the surface runoff patterns. The steeper the slope (e.g., increasing from $5^{\circ}$ to $25^{\circ}$ ), the less the surface ponding depth (accordingly decreasing from about $11 \mathrm{~mm}$ to about $4 \mathrm{~mm}$ ), given all other conditions unchanged. This observation is consistent with that from Figure 10(d).

\section{Summary and Conclusions}

The paper presents integrative analyses of rainwater infiltration and surface runoff for slopes subjected to short-duration high-intensity rainfall events. Soils in slope were considered to be a two-domain system, including micropore domain (soil matrix) and macropore domain. A dual-permeability model proposed in the literature was adopted to describe the rainwater movement and exchange between the two domains. A kinematic wave model was employed to describe the slope surface runoff of rainwater. The two models were jointly used to carry out an integrative analysis of rainwater infiltration inside slope soils and runoff on slope surface based on boundary conditions on slope surface. Laboratory tests were then conducted to evaluate the ability of using the two models for integrative analysis. The main conclusions drawn from this study are as follows.

(1) The approach proposed in this study of using dualpermeability model coupled with kinematic wave model 
is applicable for description of rainwater movement inside slope soils and runoff on slope surface. The approach is satisfactorily accurate on average and the spread in prediction is very small from a statistical point of view based on comparisons between predicted outcomes and laboratory testing outcomes.

(2) The presence of macropores in slope would change the infiltration of rainwater dramatically based on the maximum depth of wetting front. With the existence of macropores, the maximum depth of wetting front can be one order of magnitude larger than that for slopes without macropores. This highlights the need to take macropores into account in analyses of rainwater infiltration and movement in slopes and in slope stability analyses under rainfall conditions. Also, for slopes without the presence of macropores, the great majority of rainwater would become surface runoff which increases the risk of flooding hazards, whereas for slopes with macropores, a significant amount of rainwater would infiltrate into the soils, which decreases the risk of flooding hazards but increases the risk slope stability failures in the meanwhile.

(3) The influences of rainfall intensity, initial pore water pressure, coefficient of permeability of soil matrix, and slope angle are significant on the movement of rainwater inside slope soils but are practically insignificant on depth of surface ponding on slope surface.

\section{Conflicts of Interest}

The authors declare that there are no conflicts of interest regarding the publication of this paper.

\section{Acknowledgments}

The authors are grateful for financial support from the National Natural Science Foundation of China (nos. 41302215 and 41772297) and the Natural Sciences and Engineering Research Council of Canada (NSERC).

\section{References}

[1] L. Zhang, J. Li, X. Li, J. Zhang, and H. Zhu, Rainfall-Induced Soil Slope Failure: Stability Analysis and Probabilistic Assessment, CRC Press, Boca Raton, Fla, USA, 2016.

[2] A. O. Akan and B. C. Yen, "Mathematical model of shallow water flow over porous media," Journal of Hydraulic Engineering, vol. 107, no. 4, pp. 479-494, 1981.

[3] M. B. Abbott, J. C. Bathurst, J. A. Cunge, P. E. O'Connell, and J. Rasmussen, "An introduction to the European Hydrological System-Systeme Hydrologique Europeen, 'SHE', 2: structure of a physically-based, distributed modelling system," Journal of Hydrology, vol. 87, no. 1-2, pp. 61-77, 1986.

[4] N. K. Garg and D. J. Sen, "Integrated physically based rainfallrunoff model using FEM," Journal of Hydrologic Engineering, vol. 6 , no. 3, pp. 179-188, 2001.

[5] E. Bautista, D. Zerihun, A. J. Clemmens, and T. S. Strelkoff, "External iterative coupling strategy for surface-subsurface flow calculations in surface irrigation," Journal of Irrigation and Drainage Engineering, vol. 136, no. 10, Article ID 007010QIR, pp. 692-703, 2010.
[6] M. Banti, T. Zissis, and E. Anastasiadou-Partheniou, "Furrow irrigation advance simulation using a surface-subsurface interaction model," Journal of Irrigation and Drainage Engineering, vol. 137, no. 5, pp. 304-314, 2011.

[7] Q. Dong, D. Xu, S. Zhang, M. Bai, and Y. Li, "A hybrid coupled model of surface and subsurface flow for surface irrigation," Journal of Hydrology, vol. 500, no. 14, pp. 62-74, 2013.

[8] G. Schmitz, R. Haverkamp, and O. Velez, "A coupled surfacesubsurface model for shallow water flow over initially dry soil," in Proceedings of the 21st Congress IAHR, vol. 1, pp. 23-30, 1985.

[9] R. Wallach, G. Grigorin, and J. Rivlin, "The errors in surface runoff prediction by neglecting the relationship between infiltration rate and overland flow depth," Journal of Hydrology, vol. 200, no. 1-4, pp. 243-259, 1997.

[10] M. Morita and B. C. Yen, "Modeling of conjunctive two-dimensional surface-three-dimensional subsurface flows," Journal of Hydraulic Engineering, vol. 128, no. 2, pp. 184-200, 2002.

[11] S. E. Allaire, S. Roulier, and A. J. Cessna, "Quantifying preferential flow in soils: a review of different techniques," Journal of Hydrology, vol. 378, no. 1-2, pp. 179-204, 2009.

[12] P. F. Germann and K. Beven, "Kinematic wave approximation to infiltration into soils with sorbing macropores," Water Resources Research, vol. 21, no. 7, pp. 990-996, 1985.

[13] H. H. Gerke and M. T. van Genuchten, "A dual-porosity model for simulating the preferential movement of water and solutes in structured porous media," Water Resources Research, vol. 29, no. 2, pp. 305-319, 1993.

[14] J. P. Gwo, P. M. Jardine, G. V. Wilson, and G. T. Yeh, "A multiplepore-region concept to modeling mass transfer in subsurface media," Journal of Hydrology, vol. 164, no. 1-4, pp. 217-237, 1995.

[15] J. Hosang, "Modelling preferential flow of water in soils - a twophase approach for field conditions," Geoderma, vol. 58, no. 3-4, pp. 149-163, 1993.

[16] H. H. Gerke and M. T. van Genuchten, "Evaluation of a first-order water transfer term for variably saturated dual-porosity flow models," Water Resources Research, vol. 29, no. 4, pp. 1225-1238, 1993.

[17] J. Šimunek, N. J. Jarvis, M. T. van Genuchten, and A. Gardenas, "Review and comparison of models for describing nonequilibrium and preferential flow and transport in the vadose zone," Journal of Hydrology, vol. 272, no. 1-4, pp. 14-35, 2003.

[18] V. T. Chow, D. R. Maidment, and L. W. Mays, Applied Hydrology, McGraw-Hill, New York, NY, USA, 1988.

[19] W. R. Walker and G. V. Skogerboe, Surface Irrigation: Theory and Practice, Englewood Cliffs: Prentice Hall College Div, New Jersey, NJ, USA, 1987.

[20] G. Huang and G.-T. Yeh, "Comparative study of coupling approaches for surface water and subsurface interactions," Journal of Hydrologic Engineering, vol. 14, no. 5, pp. 453-462, 2009.

[21] T. Vogel, H. H. Gerke, R. Zhang, and M. T. Van Genuchten, "Modeling flow and transport in a two-dimensional dualpermeability system with spatially variable hydraulic properties," Journal of Hydrology, vol. 238, no. 1-2, pp. 78-89, 2000.

[22] N. J. Jarvis, "A review of non-equilibrium water flow and solute transport in soil macropores: principles, controlling factors and consequences for water quality," European Journal of Soil Science, vol. 58, no. 3, pp. 523-546, 2007.

[23] B. Arora, B. P. Mohanty, and J. T. McGuire, "Uncertainty in dual permeability model parameters for structured soils," Water Resources Research, vol. 48, no. 1, pp. 1-17, 2008. 
[24] H. H. Gerke and M. T. Van Genuchten, "Macroscopic representation of structural geometry for simulating water and solute movement in dual-porosity media," Advances in Water Resources, vol. 19, no. 6, pp. 343-357, 1996.

[25] J. M. Köhne and B. P. Mohanty, "Water flow processes in a soil column with a cylindrical macropore: experiment and hierarchical modeling," Water Resources Research, vol. 41, no. 3, pp. 221-231, 2005.

[26] D. Paul and Z. David, Applied Partial Differential Equations, Dover Publications, New York, NY, USA, 2002.

[27] D. W. Peaceman and H. H. Rachford, "The numerical solution of parabolic and elliptic differential equations," Society for Industrial and Applied Mathematics, vol. 3, no. 1, pp. 28-41, 1955.

[28] D. Jim, "Alternating direction methods for three space variables," Numerische Mathematik, vol. 4, no. 1, pp. 41-63, 1962.

[29] Q. Wu, L. Wang, and F. Wu, "Tillage - impact on infiltration of the Loess Plateau of China," Acta Agriculturae Scandinavica, Section B - Soil \& Plant Science, vol. 64, no. 4, pp. 341-349, 2014.

[30] R. D. Holtz, W. D. Kovacs, and T. C. Sheahan, An Introduction to Geotechnical Engineering, PEARSON, Upper Saddle River, New Jersey, NJ, USA, 2nd edition, 2010.

[31] D. G. Fredlund and H. Rahardjo, Soil Mechanics for Unsaturated Soils, John Wiley and Sons, Inc, New York, NY, USA, 1993.

[32] M. T. van Genuchten, "A closed-form equation for predicting the hydraulic conductivity of unsaturated soils," Soil Science Society of America Journal, vol. 44, no. 5, pp. 892-898, 1980.

[33] Y. Mualem, "A new model for predicting the hydraulic conductivity of unsaturated porous media," Water Resources Research, vol. 12 , no. 3, pp. 513-522, 1976. 


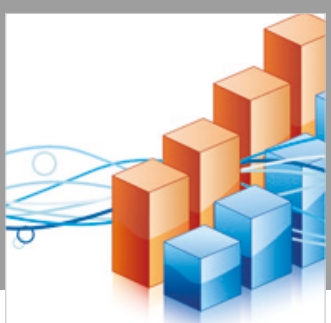

Advances in

Operations Research

\section{-n-m}
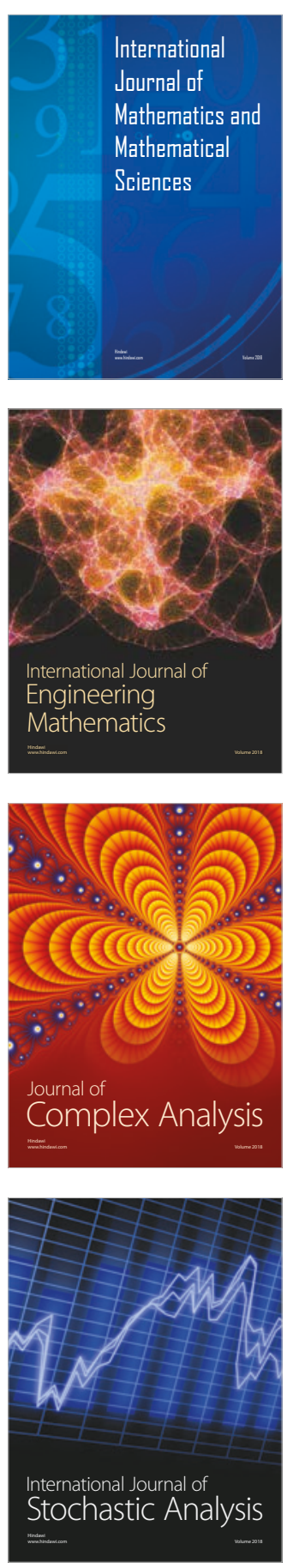
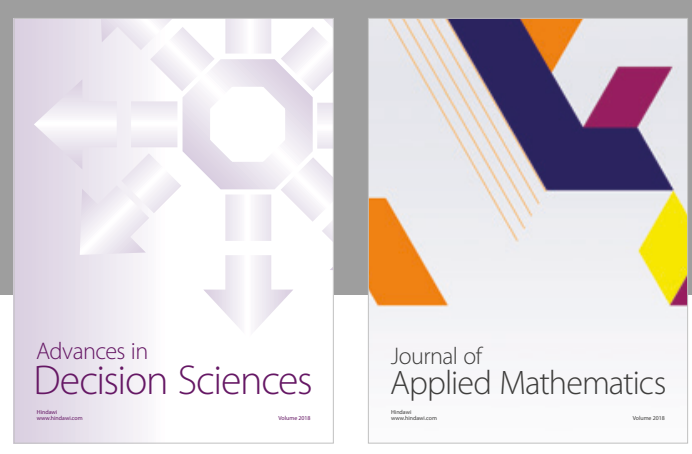

Journal of

Applied Mathematics
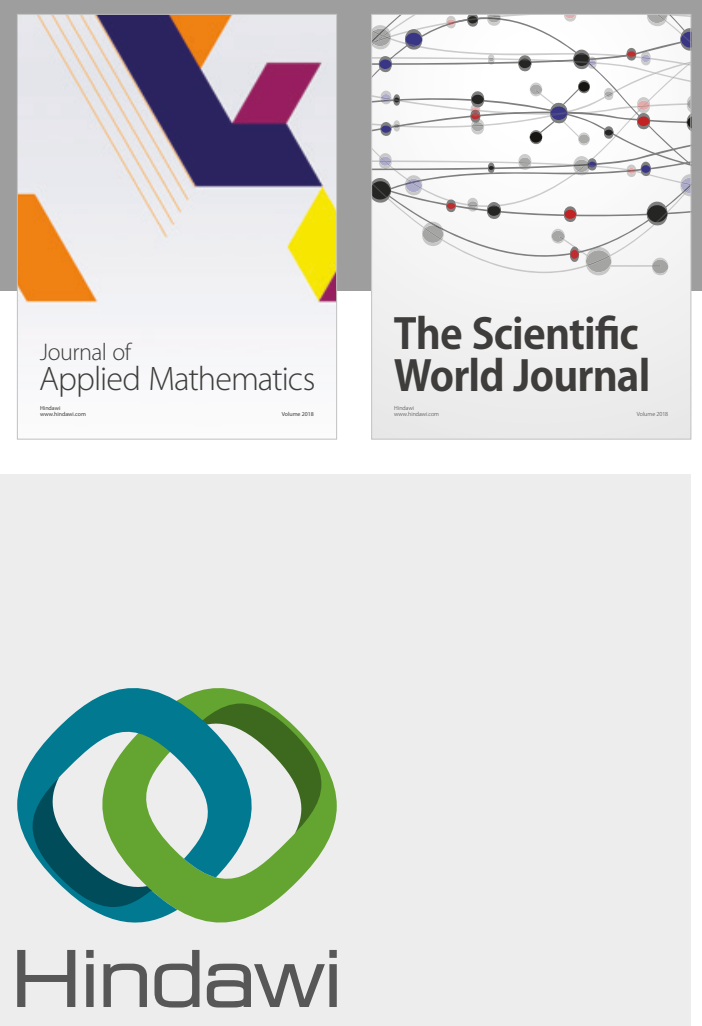

Submit your manuscripts at

www.hindawi.com

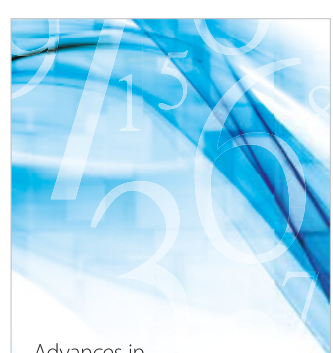

Advances in
Numerical Analysis
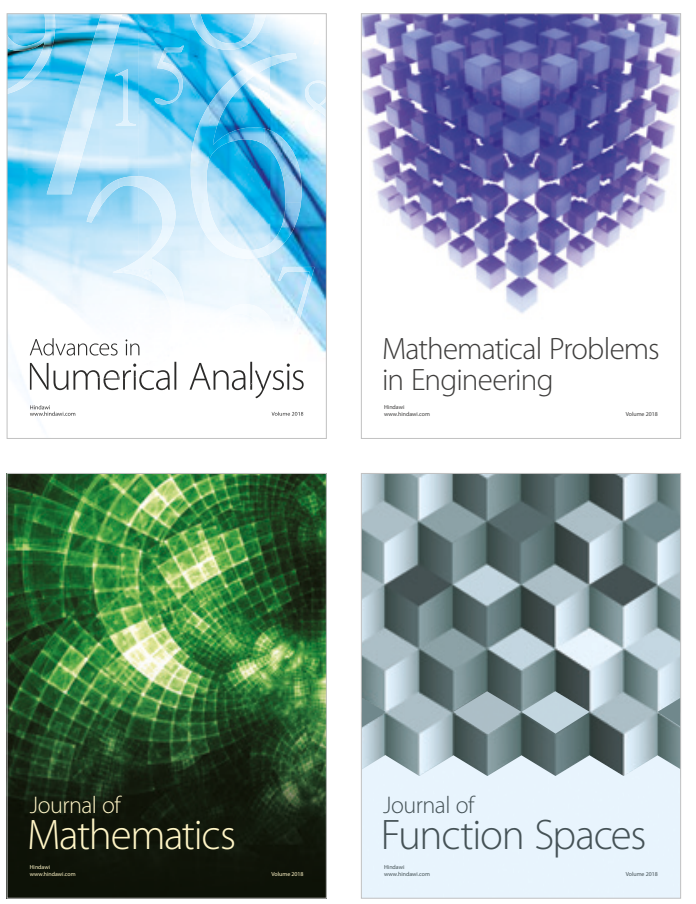

Mathematical Problems in Engineering

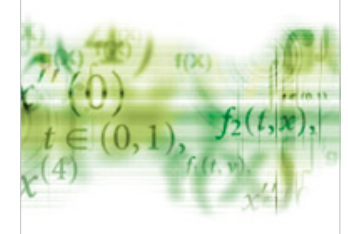

International Journal of

Differential Equations

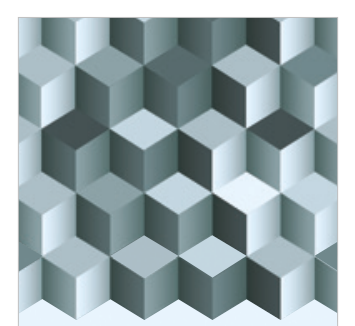

Journal of

Function Spaces

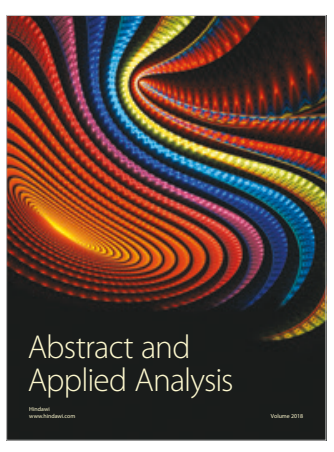

The Scientific

World Journal

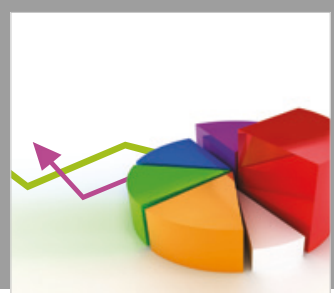

Journal of

Probability and Statistics
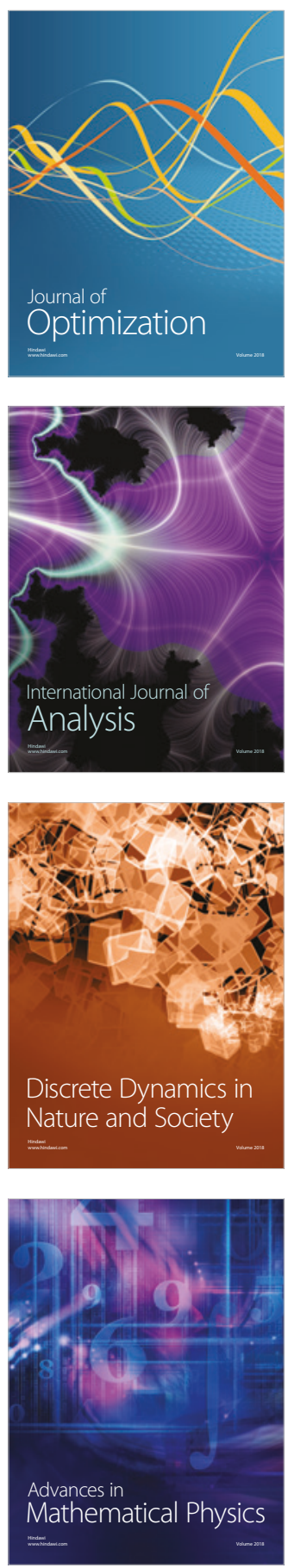